\title{
Philosophiques
}

\section{Allen Buchanan, Secession : The Morality of Political Divorce from Fort Sumter to Lithuania and Quebec, Boulder, Westview Press, 1991.}

\section{Daniel M. Weinstock}

Volume 20, numéro 1, printemps 1993

URI : https://id.erudit.org/iderudit/027221ar

DOI : https://doi.org/10.7202/027221ar

Aller au sommaire du numéro

Éditeur(s)

Société de philosophie du Québec

ISSN

0316-2923 (imprimé)

1492-1391 (numérique)

Découvrir la revue

Citer ce compte rendu

Weinstock, D. M. (1993). Compte rendu de [Allen Buchanan, Secession: The Morality of Political Divorce from Fort Sumter to Lithuania and Quebec, Boulder, Westview Press, 1991.] Philosophiques, 20(1), 228-231.

https://doi.org/10.7202/027221ar d'utilisation que vous pouvez consulter en ligne.

https://apropos.erudit.org/fr/usagers/politique-dutilisation/ 


\section{Allen Buchanan, Secession : The Morality of Political Divorce from Fort Sumter to Lithuania and Quebec, Boulder, Westview Press, 1991.}

\section{par Daniel M. Weinstock}

Ce livre, écrit par l'un des plus importants praticiens américains de l'éthique appliquée, passionnera immanquablement les philosophes québécois soucieux de réfléchir de manière cohérente aux graves questions morales et juridiques auxquelles le Québec aura à faire face dans les années à venir. Comme Buchanan le constate, le problème de la sécession n'a jamais été traité de manière systèmatique par la philosophie politique contemporaine, et ce. malgré son importance dans l'actualité internationale. Son livre tombe donc réellement à point.

La grande originalité du livre de Buchanan est qu'il cherche à rendre compte de l'existence d'un droit collectif à la sécession à partir des ressources conceptuelles du libéralisme philosophique contemporain. Le libéralisme a toujours été hostile à l'idée qu'il puisse exister un droit dont le bénéficiaire n'était pas l'individu, la notion de «droit » ayant dans l'économie conceptuelle libèrale le rôle de protéger l'individu de la tyrannie que peuvent parfois exercer les collectivités. La tradition libérale a de plus ignoré le problème de la sécession, puisque les solutions qu'elle propose aux problèmes de l'organisation politique de la société se veulent universelles, et vont donc à l'encontre du particularisme qui semble sous-tendre tout mouvement séparatiste. Selon Buchanan, la notion de droit individuel existe pour protéger les intérêts dominants des individus; or, l'individu a un intérêt dominant à ce que les « biens » que lui assure son appartenance à un groupe humain concret soient protégés. En particulier - et ici Buchanan suit l'analyse du philosophe canadien Will Kymlicka -, la communauté fournit à chaque individu un contexte de valeurs dont il a besoin afin d'exercer de manière significative sa faculté de choix (p. 39). Il est donc possible de fournir une justification individualiste let donc 
irréprochable d'un point de vue libérall de droits dont les bénéficiaires seraient des communautés.

Ayant établi l'importance pour la pensée libérale de reconnaître certains droits collectifs, la stratégie de Buchanan est simple : il examine dans un premier temps les arguments justifiant un droit à la sécession, et il recense. deuxièmement. les considérations morales qui semblent aller à l'encontre de la reconnaissance d'un tel droit. Finalement. il fournit brièvement certaines indications facilitant l'expression constitutionnelle du droit limité à la sécession que son analyse morale aura dégagé.

Quelles sont les considérations morales principales qui pourraient être invoquées par une communauté cherchant à se séparer de l'État dont elle fait partie? Buchanan estime que nous avons intuitivement tendance à répondre de deux manières différentes à cette question, toutes les deux insatisfaisantes: premièrement, nous disons parfois que c'est en vertu du fait qu'elle a été la victime d'injustices passées aux mains de l'État dont elle cherche à se séparer qu'une communauté possède un droit à la sécession. Selon Buchanan, cette réponse est insatisfaisante, puisqu'elle demeure trop vague quant au type d'injustice dont il doit être question pour justifier la sécession ; et elle ignore le fait qu'il peut exister d'autres justifications de ce droit ne passant pas du tout par l'idée d'injustice (par exemple la volonté de préserver une culture dont l'existence est menacée). Deuxièmement, nous avons tendance à justifier la sécession en invoquant le droit à l'autodétermination des peuples. Selon Buchanan, cette intuition ne peut survivre à un examen philosophique soutenu : d'abord, la reconnaissance d'un tel droit n'implique pas nécessairement un droit à la souveraineté politique ; et ensuite, la notion d'autodétermination cache plus qu'elle ne révèle. Elle est en elle-même dénuée de signification réelle, et remplit d'habitude un rôle rhétorique ou émotif plutôt que substantiel. Le genre de considération morale que dissimule tout appel au droit à l'autodétermination ne peut être évalué que si les valeurs plus spécifiques et concrètes qui sont en jeu sont mises à jour. Selon Buchanan, « the moral force of any particular specification of self-determination depends upon the more basic values that implementing it might serve in a particular context $\gg$ (p. 50 ).

Ayant écarté les réponses « intuitives » que nous avons tendance à offrir à la question de la justification de la sécession, Buchanan passe en revue une douzaine de justifications plus précises et concrètes. Les plus importantes selon Buchanan semblent être celles qui font appel à la volonté que manifeste un groupe d'échapper aux mesures distributives discriminatoires que lui impose l'État dont il cherche à se séparer ; à la volonté qu'il manifeste de préserver sa culture contre une menace d'assimilation; et à la rectification de torts territoriaux (annexion, invasion) perpétrés à l'endroit du groupe réclamant sa souveraineté.

Les discussions que Buchanan consacre à l'élucidation de chacun de ces points sont toujours marquées par une impressionnante appréciation de la complexité des situations au sein desquelles les revendications souverainistes doivent être accommodées. Buchanan démontre que même les revendications faisant appel à l'injustice des mesures distributives discriminatoires ou à la préservation de la culture ne peuvent donner lieu à un droit à la sécession si elles ne sont pas accompagnées par un droit sur le territoire auquel elles se 
rattachent. De plus, Buchanan insiste sur le fait que la possession par un groupe d'un droit complet à la sécession devra parfois être mitigée par la reconnaissance d'obligations morales envers l'État dont il cherche à se séparer. Cette appréciation des subtilités morales accompagnant le problème de la sécession est particulièrement évidente dans la discussion réservèe par Buchanan à l'argument prosécessionniste faisant appel à la préservation de la culture. Buchanan estime qu'un tel appel ne peut réellement être à la base d'un droit à la sécession si le groupe en question ne peut montrer qu'aucune autre mesure politique ou légale ne pourrait garantir la préservation de sa culture, et s'il ne peut montrer que lui seul a un droit exclusif au territoire sur lequel il espère fonder un état souverain. En vertu de ces considérations, Buchanan manifeste un certain scepticisme quant à la justification morale du droit à la sécession réclamé par le Québec (p. 6r-64).

Buchanan cite un nombre de considérations qui, en certaines circonstances, seraient en mesure d'invalider les revendications souverainistes d'un groupe, et même de justifier une opposition active à ses démarches. Dans des cas très limités, on pourrait résister à la sécession lorsque celle-ci aurait pour effet de nuire outrancièrement aux attentes légitimes des autres groupes membres de l'État d'origine; il en irait de même lorsque la sécession aurait des conséquences morales désastreuses pour l'État d'origine. La pensée libérale justifierait également selon Buchanan une opposition à la sécession dans des cas où le groupe sécessionniste aurait l'intention de fonder un État ne reconnaissant pas les droits fondamentaux, et interdisant ainsi à ses membres futurs le privilège de jouir de tels droits.

Buchanan estime que la considération qui justifiera le plus souvent l'opposition à la sécession est lorsque celle-ci nécessiterait une saisie illégitime de territoire ou de ressources. Il se pourrait que l'État d'origine ait investi de manière significative dans l'infrastructure économique de la région cherchant à se séparer, auquel cas le droit à la sécession doit s'accompagner d'une obligation à compenser l'Etat pour ses investissements perdus. Dans le cas de territoires contestés, il se pourrait selon Buchanan quaucun droit à la sécession n'existe : afin d'avoir réellement droit à « son » territoire, le groupe sécessionniste doit démontrer que l'état d'origine n'est plus légitimement souverain sur ce territoire, et que le groupe, lui, l'est, ou tout au moins devrait l'être. Ces conditions seront assez faciles à satisfaire dans des cas où ce n'est qu'à cause d'une injustice passée que les sécessionnistes n'ont plus de droit souverain sur leur territoire, et que ce territoire leur appartenait précédemment de droit. Elles seront beaucoup plus difficiles à satisfaire dans des cas où l'histoire de l'acquisition des territoires en question est plus floue.

Buchanan conclut son livre en envisageant plusieurs scénarios possibles qui donneraient une expression constitutionnelle au droit limité à la sécession qu'il croit avoir dégagé jusque-là dans son livre. Toute formule constitutionnelle devra incarner à la fois une reconnaissance des considérations morales légitimes qui peuvent pousser un peuple à vouloir se séparer d'un État, et des limites qui doivent circonscrire ce droit. Il s'agira selon Buchanan de reconnaître constitutionnellement que tout peuple a le droit de se séparer, mais d'y imposer certains obstacles et conditions, aussi bien substantiels que de l'ordre de la procédure, l'intention étant d'en arriver à une adéquation aussi 
forte que possible entre le droit moral à la sécession, et le droit tel que constitutionnellement expriné.

J'espère que je n'ai plus à dire l'importance de ce livre. Il comble un manque sérieux dans la littérature philosophique d'allégeance libérale, et soulève un nombre important de questions que toute contribution ultérieure au problème de la sécession se devra d'adresser. Je me permets ici tout simplement deux réserves, ayant toutes deux trait à la discussion réservée par Buchanan au problème de la « préservation de la culture » comme motif de la sécession. Premièrement, quoique Buchanan recomnaisse qu'une société dont la culture est en réel danger de disparition devrait avoir le droit de constituer son propre Etat, il se pourrait que sa conception de la culture soit assez étroite. En traitant particulièrement du cas du Québec, Buchanan évoque un certain nombre de questions que nous pourrions nous poser afin d'obtenir des données «dures» (《hard data ») (p. 62) sur le niveau réel de danger auquel fait face une société. Or, celles-ci ont toutes trait à des questions d'ordre linguistique et artistique. Buchanan ne semble pas envisager la possibilité qu'une des manifestations principales de la culture d'un peuple est justement la manière dont il se gouverne.

Deuxièmement, Buchanan estime que, du point de vue de la pensée libérale, il est préférable que la fin de la préservation de la culture soit atteinte par des mesures légales et politiques en deçà de la sécession. Selon Buchanan. la sécession motivée par des considérations de préservation de culture voit la valeur principale d'un Etat souverain comme étant le fait qu'il leur permet de limiter les influences de cultures étrangères par le moyen du contrôle de ses frontières ( $p$. 58). Puisque le même résultat peut être obtenu par des moyens législatifs n'exigeant pas la dissolution de l'Etat d'origine. Buchanan estime qu'il serait preférable de les atteindre par le truchement d'un Etat libéral multiculturel. parce que celui-ci serait davantage équipé pour parer les effets « illibéraux » qui pourraient découler des mesures politiques et légales nécessaires pour protéger des cultures minoritaires. Bien que je partage la préférence de Buchanan, je crois que ce dernier n'est pas suffisamment conscient de ce que cette préférence lui coûte. En fait, ce que Buchanan nous dit, c'est que lorsqu'il y a conflit potentiel entre valeurs libérales et particularités communautaires, ce sont les valeurs libérales qui doivent l'emporter. Ne s'agit-il pas là d'une réadmission des prétentions universalisantes du libéralisme que Buchanan croyait devoir écarter pour pouvoir incorporer à la tradition libérale une reconnaissance de l'importance de la question de la sécession?

\section{Département de philosophic}

Université de Montréal / Columbia University 